\title{
JOURNAL OF INVERSE AND ILL-POSED PROBLEMS
}

\section{EDITOR-IN-CHIEF}

Sergey I. Kabanikhin, Novosibirsk

\section{MANAGING EDITOR}

Maxim A. Shishlenin, Novosibirsk

\section{ADVISORY BOARD}

Avner Friedman, Columbus

Rudolf Gorenflo, Berlin

Peter Lax, New York

Zuhair Nashed, Orlando

Vladimir G. Romanov, Novosibirsk

Pierre Sabatier, Montpellier

Vladimir V. Vasin, Ekaterinburg

\section{EDITORIAL BOARD}

Alexander L. Ageev, Ekaterinburg

Giovanni Alessandrini, Trieste

Yurii Ye. Anikonov, Novosibirsk

H. Thomas Banks, Raleigh

Michael I. Belishev, St. Petersburg

Alexander L. Bukhgeim, Novosibirsk/Whichita

Jin Cheng, Shanghai

Christian Clason, Graz

Alexander M. Denisov, Moscow

Heinz W. Engl, Vienna

Maurizio Grasselli, Milan

Dinh Nho Ha'o, Hanoi

Alemdar Hasanoglu, Izmir
Bernd Hofmann, Chemnitz Mikhail Yu. Kokurin, Yoshkar-Ola Rainer Kress, Göttingen

Daniel Lesnic, Leeds

Alfred K. Louis, Saarbrücken

Andreas Neubauer, Linz

Roman G. Novikov, Paris/Moscow

Lassi Paivarinta, Helsinki

Valery V. Pickalov, Novosibirsk

Alexey I. Prilepko, Moscow

Vladislav V. Pukhnachev, Novosibirsk

Paul Sacks, Ames

Otmar Scherzer, Vienna

Samuli Siltanen, Helsinki

Gunther Uhlmann, Seattle

Yanfei Wang, Beijing

Anatoly G. Yagola, Moscow

Masahiro Yamamoto, Tokyo

Vyacheslav A. Yurko, Saratov

Jun Zou, Hong Kong

\section{DE GRUYTER}


JOURNAL OF INVERSE AND ILL-POSED PROBLEMS aims to present original articles on the theory, numerics and applications of inverse and ill-posed problems. These inverse and ill-posed problems arise in mathematical physics and mathematical analysis, geophysics, acoustics, electrodynamics, tomography, medicine, ecology, financial mathematics etc. Articles on the construction and justification of new numerical algorithms of inverse problem solutions are also published.

All information regarding notes for contributors, subscriptions, Open access, back volumes and orders is available online at www.degruyter.com/jiip.

ABSTRACTED/INDEXED IN Current Contents/PC \& ES, Science Citation Index Expanded, Journal Citation Reports/Science Edition, Mathematical Reviews and Zentralblatt MATH.

ISSN 0928-0219 · e-ISSN 1569-3945 · CODEN JIIPA4

RESPONSIBLE EDITOR Sergey I. Kabanikhin, Institute of Computational Mathematics and Mathematical Geophysics, Russian Academy of Sciences, Siberian Branch, prospect Lavrentieva 6, 630090 Novosibirsk, Russia.

Email: Kabanikhin@sscc.ru

JOURNAL MANAGER Theresa Haney, De Gruyter, Genthiner Straße 13, 10785 Berlin, Germany. Tel.: +49 (0)30 26005 - 375, Fax: +49 (0)30 26005 - 250 .

Email: theresa.haney@degruyter.com

RESPONSIBLE FOR ADVERTISEMENTS Panagiota Herbrand, De Gruyter, Rosenheimer Straße 143,

81671 München, Germany.

Tel.: +49 (0)89 76902 - 394, Fax: +49 (0)89 76902 - 350

Email: panagiota.herbrand@degruyter.com

(C) 2014 Walter de Gruyter GmbH, Berlin/Boston

TYPESETTING Dimler \& Albroscheit, Müncheberg

PRINTING Franz X. Stückle Druck und Verlag e.K., Ettenheim Printed in Germany

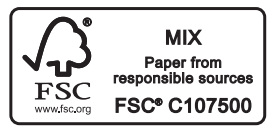




\section{F. ZOUYed, F. REBBANI}

A modified quasi-boundary value method for an ultraparabolic

ill-posed problem

N. Bondarenko, G. Freiling

An inverse problem for the quadratic pencil of non-self-adjoint matrix operators on the half-line

M. RIPLINGER, M. SPIESS

Numerical inversion of the spherical Radon transform and the cosine transform using the approximate inverse with a special class of locally supported mollifiers

I. G. KAZANTSEV, S. SCHMidT

A spherical $\mathrm{x}$-ray transform and hypercube sections

J. FLEMMING

Regularization of autoconvolution and other ill-posed quadratic equations by decomposition

A. ERDEM

An adaptive algorithm for determination of source terms in a linear parabolic problem

V. VAsin, S. GeORGE

Expanding the applicability of Tikhonov's regularization and iterative approximation for ill-posed problems 
